\title{
Colonoscopy in Acute Appendicitis
}

\author{
Vincent Zimmer, Bernhard Juengling and Frank Lammert
}

Key words: appendicitis, right lower quadrant pain, endoscopic diagnosis

(Inter Med 49: 2273, 2010)

(DOI: 10.2169/internalmedicine.49.3891)
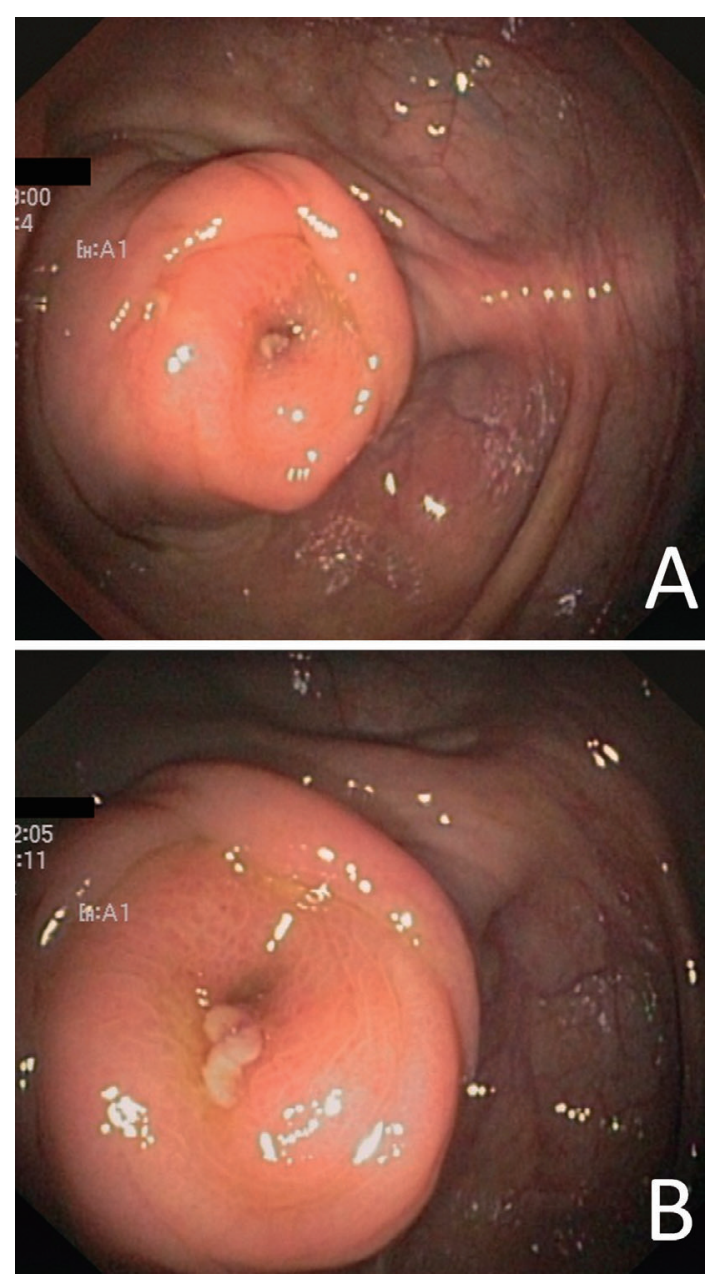

Picture 1.
A 46-year-old man with fluctuating abdominal pain and slight elevation of inflammatory markers (C-reactive protein $22.2 \mathrm{mg} / \mathrm{L}$, normal <5) was referred for ileocolonoscopy after surgical evaluation including a non-diagnostic ultrasound examination. Endoscopy revealed an appendiceal orifice with profound intraluminal bulging (Picture 1A) and spontaneous purulent discharge as well as minor mucosal erythema (Picture 1B). The patient underwent an uneventful appendectomy including cecal pole resection. Final pathologic evaluation confirmed the presence of ulcero-phlegmonous appendicitis with accentuated involvement of the appendix base.

The diagnosis of acute appendicitis is occasionally made by endoscopy in the presence of atypical symptoms and inconclusive imaging findings (1). In such a setting, endoscopic evaluation may help to rule out differential diagnoses, e.g. ileocecal tumors or inflammatory bowel disease (2). Endoscopic features include orificial buldging and edematous mucosal alterations. Sometimes, active putride secretion is present, potentially contributing to an attenuation of the clinical course.

\section{References}

1. Chang HS, Yang SK, Myung SJ, et al. The role of colonoscopy in the diagnosis of appendicitis in patients with atypical presentations. Gastrointest Endosc 56: 343-348, 2002.

2. Manz M, Peter S, Beglinger C. Image of the month. An atypical approach to appendicitis. Clin Gastroenterol Hepatol 2008; 6: Epub 2008 Feb 6. 